\title{
Endoscopic drainage of gastric wall mycetoma
}

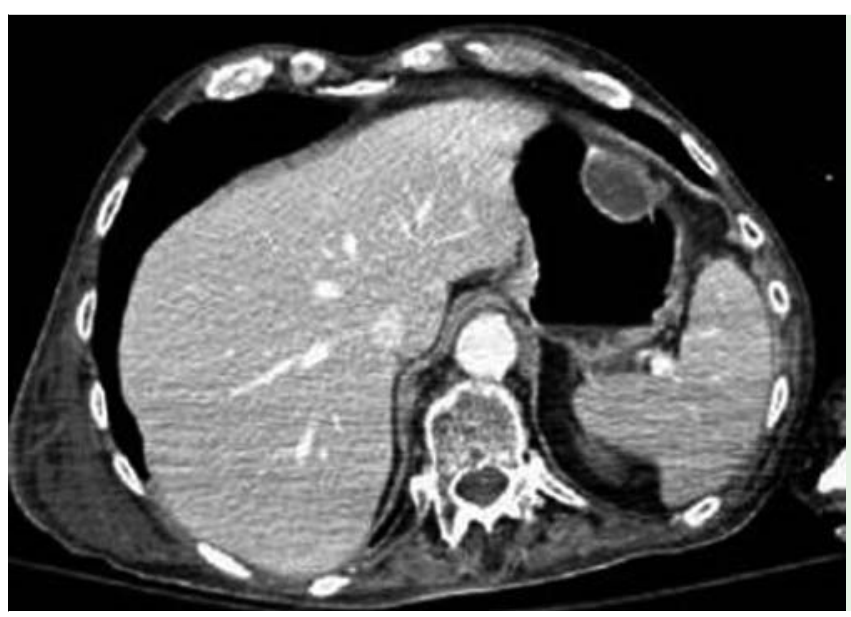

Fig. 1 An encapsulated fluid collection $(34 \mathrm{~mm} \times 20 \mathrm{~mm})$ probably within the gastric wall, shown at computed tomography (CT) in a 69-year-old patient who had previously undergone surgical necrosectomy for acute hemorrhagic necrotizing pancreatitis complicated by a pancreatic fistula.

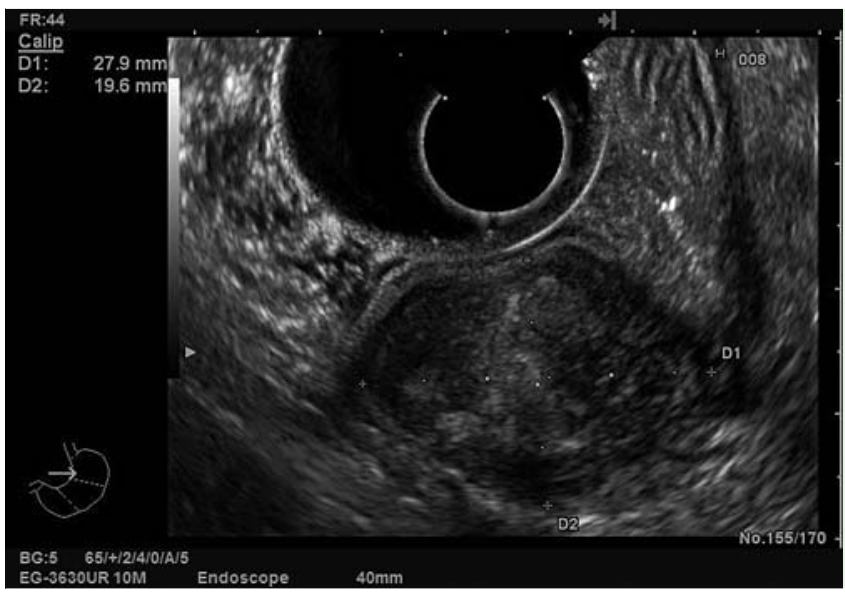

Fig. 2 At endoscopic ultrasound (EUS) the mycetoma appears as a submucosal hyperechogenic and inhomogeneous mass located in the lesser curvature of the gastric bodyfundus.
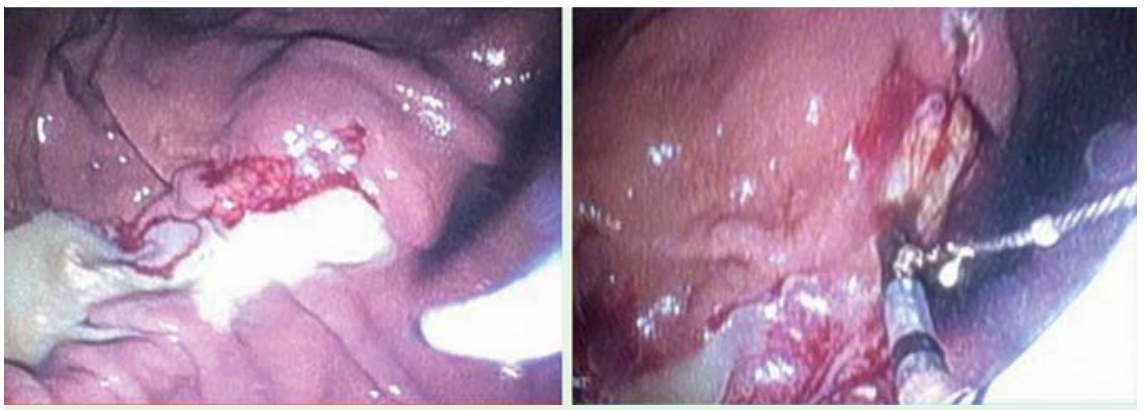

Fig. 3 Drainage of the mycetoma using a precut needle and cannulotome; a dense whitish fluid begins to flow.

A 69-year-old patient was referred to our unit for further investigation of an encapsulated fluid collection $(34 \mathrm{~mm} \times 20 \mathrm{~mm})$ detected within the gastric wall at abdominal computed tomography (CT) (๑ Fig. 1).

The patient had previously undergone surgical necrosectomy for acute hemorrhagic necrotizing pancreatitis complicated by a pancreatic fistula. In the late postoperative course he had developed fever during antibiotic treatment with mero- penem that he had been receiving for 15 days, and CT revealed the encapsulated collection described above.

An upper gastrointestinal endoscopy was done. This showed an elevated lesion covered by normal-appearing mucosa located on the lesser curvature of the gastric fundus-body. Endoscopic ultrasound (EUS) showed a submucosal hyperechoic inhomogeneous mass ( Fig.2). EUSguided fine needle aspiration (FNA) with a $19 G$ needle was performed. Histological examination demonstrated the presence of necrotic tissue, inflammatory cells, and fungal hyphae. The mycetoma was drained under endoscopic visualization ( Fig. 3), using a precut needle (HPC-2; Cook Medical, Limerick, Ireland) and a cannulotome (CCPT-25; Cook Medical), with flow of a dense, whitish, partially corpusculated fluid from the collapsing collection. Saline solution lavages were done in order to ensure the complete emptying of the mycetoma. The patient's fever quickly resolved after the procedure and the lesion had completely disappeared on follow-up CT scan ( $\bullet$ Fig.4). In 1982 Cipollini et al. [1] described, in a patient with previous partial gastrectomy, an atypical gastric candidiasis that endoscopically presented as a large mass located in the gastric stump. Gastric candidiasis usually looks like multiple small white plaques [2] or pseudomembranous exudate [3] surrounded by hyperemic, edematous, and friable mucosa, but erosions [4], ulcers [5], and nodules have also been described.

Our case is notable because of the endoscopic appearance of a submucosal fungal mass, rather than the usually reported presentation, and its noninvasive drainage that avoided surgical treatment in this frail patient.

Endoscopy_UCTN_Code_CCL_1AZ_2AH

Competing interests: None

\section{Francesca Picconi ${ }^{1}$, Francesco Maria Di Matteo ${ }^{1}$, Monica Pandolfi ${ }^{1}$, Marga- reth Martino ${ }^{1}$, Roberta Rea ${ }^{1}$, Alessan- dra Bizzotto², Guido Costamagna ${ }^{2}$}

${ }^{1}$ Digestive Endoscopy Unit, Campus Bio-Medico, University of Rome, Rome 2 Surgical Endoscopy Unit, Sacred Heart Catholic University of Rome, Rome

\section{References}

1 Cipollini F, Altila F. Mycetoma of the gastric stump. Gastrointest Endosc 1982; 28: $220-$ 221

2 Cipollini F, Altila F. Candidiasis of the small intestine. Gastroenterology 1981; 81: 825 826

3 Eras P, Goldstein NL, Sherlock P. Candida infection of the gastrointestinal tract. Medicine (Baltimore) 1972; 51: $367-379$

4 Lombardo L, Pera A, Genovesio L et al. Duodenal mycosis during carbenoxolone and cimetidine treatment. Lancet 1979; 1 (8116): 607-608

5 Mohtashemi H, Davidson FZ. Candidiasis and gastric ulcer. Am J Dig Dis 1973; 18: $915-$ 919 


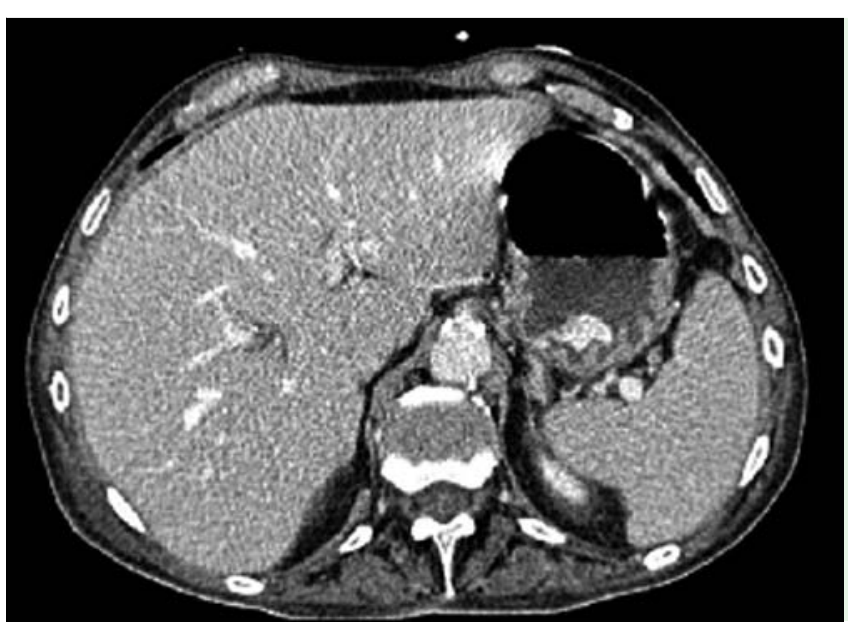

Fig.4 At follow-up computed tomography (CT) scan the mycetoma had completely disappeared.

\section{Bibliography}

Dol http://dx.doi.org/

10.1055/s-0034-1365094

Endoscopy 2014; 46: E163-E164

(c) Georg Thieme Verlag KG

Stuttgart · New York

ISSN 0013-726X

\section{Correspondence}

\section{Francesca Picconi, MD}

Digestive Endoscopy Unit, Campus Bio-Medico University of Rome

Via Alvaro del Portillo 200

00128, Rome

Italy

Fax: +39-06-225411658

f.picconi@unicampus.it 